\title{
ANALYSIS OF THE BEHAVIOR OF SPORTS PERFORMANCE IN KYOKUSHIN, SUBJECTED TO SPECIALIZED INVESTIGATIONS
}

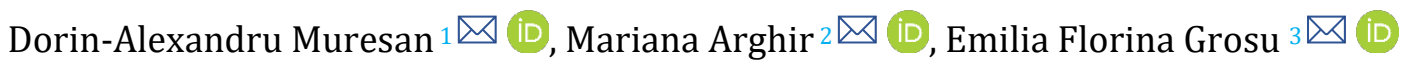 \\ ${ }^{1}$ Ph. d Student, Faculty of Physical Education and Sport, "Babeș-Bolyai” University, Cluj-Napoca, România \\ ${ }^{2}$ Professor Dr. Mechanical Engineering Department of Mechanical Engineering Systems, Technical University \\ of Cluj-Napoca, România \\ ${ }^{3}$ Professor Dr. Habil, Faculty of Physical Education and Sport, "Babeș-Bolyai” University, Cluj-Napoca, \\ România
}

Received 15 December 2021

Accepted 5 January 2022

Published 31 January 2022

\section{CorrespondingAuthor}

Dorin-Alexandru Muresan,

alex.d.muresan@gmail.com

DOI

10.29121/granthaalayah.v10.i1.2022 .4474

Funding: This research received no specific grant from any funding agency in the public, commercial, or not-for-profit sectors.

Copyright: (C) 2022 The Author(s). This is an open access article distributed under the terms of the Creative Commons Attribution License, which permits unrestricted use, distribution, and reproduction in any medium, provided the original author and source are credited.

\section{ABSTRAC'T}

In the works are presented the specialized investigations, carried out by a specialist on a device for testing the individual abilities of sportive, who practice the sport of performance in Kyokushin. The investigations are carried out on a group of 5 male sportive, who are subjected to 8 different tests, on a motorized platform with multi-axial action, HUBER 360 - computerized equipped with its own diversified program and adapted to testing, with which the components of the individual movement of the sportive are established, but also his reactions under external actions, which may consist of hits, pushes, or fixations.

The work designed for this group of sportive is particularly important because, in this way, one can establish the abilities of the sportive to practice the sport to which he considers that he prefers performance. The investigation of the sportive can be done in advance, before a competition, to establish the vulnerability of the sportive in practicing sports. Thus, the conditions in which he can activate are established, but the sportive warns about the dangers, to which he is subjected during the competition, to be able to avoid them or to counteract them.

The investigation can be done after the competition, regardless of whether the sportive suffered an injury or not. An injury of the sportive entails the interruption of his sports activity for a determined period, in which through treatment and training the sportive restores his sports skills to participate in a new competition. With the HUBER 360 device, periodical investigations are made, to establish the evolution of the sportive during recovery, with which certain training or physical or medicinal treatments can be prescribed.

Keywords: Sportives in Kyokushin, Preliminary Investigation, Computational Study, Assessment of Injury Risks, Injury Prevention

\section{INTRODUCTION}

By choosing this research topic, we want a new approach to the evaluation and treatment of balance and injuries encountered in performance sports, realized with the help of the Huber 360 computer platform. The paper presents the investigations that are carried out on a group of 5 male athletes, who practice performance Kyokushin, all of them are part of the University team in ClujNapoca.

For a better understanding of the applied investigations, a short presentation of this sport is made. It is characterized by full contact; does not show protection to punches; they can also hit the face, but only with the foot; 
there is KO; the blow with the lower limbs is accepted. Kyokushin relies on force shots to deal as much damage as possible. This means that the sportive needs the reaction speed, as well as the strength in both the lower and upper limbs.

The primary prevention of an injury in sport is a public health priority that will be of high importance in reducing the long-term consequences of musculoskeletal injuries, as is possible in the Kyokushin competitions Emery and Pasanen (2019).

Although the risk of suffering an injury is high in certain sports, proper management can control or reduce this risk. Risk management involves a work schedule through which risks can be identified, evaluated, and intervened on them various strategies Fuller (2007).

By intervening on certain risk factors (muscle imbalances, training mistakes) that are associated with various sports accidents in young people, acute injuries and those due to overtraining could be reduced from $15 \%$ to $50 \%$. It has been observed that high-intensity or high-volume workout sessions should be periodically alternated with lower intensity programs to increase the ability to adapt to workouts and reduce the risk of overtraining Chattanooga (2015).

Given the high frequency of injuries such as the ankle sprain, it is necessary to use devices such as the Huber 360 with which the risk of suffering from a sprain at this level can be predicted by evaluation. Such assessments should be carried out at the beginning of the competitive season, allowing athletes' weaknesses to be detected with the help of safe and reproducible assessments.

\section{MATERIALS AND METHODS}

The participants of this study are 5 athletes, who practice Kyokushin performance. They are male, physically, mentally, and intellectually healthy, who have agreed to be investigated before the competitions with the Huber 360 computer device, through which it is possible to establish those behavioural insufficiencies, which must be corrected, to sustain with as little damage as possible competition Valle et al. (2017).

The centralizing situation can be found in Table 1.

Table 1 The structure of the group of Kyokushin players under investigation

\begin{tabular}{ccccc}
\hline Subject & Sex & Age & Height $[\mathbf{c m}]$ & Weight $[\mathbf{k g}]$ \\
\hline M1 & Masculine & 21 & 175 & 79 \\
M2 & Masculine & 30 & 170 & 80 \\
M3 & Masculine & 21 & 170 & 78 \\
M4 & Masculine & 40 & 181 & 100 \\
\hline M5 & Masculine & 39 & 172 & 73 \\
\hline
\end{tabular}

In the table is written the name of the subject and to this, we will refer during the investigations, which will be carried out with the HUBER 360 computerized device. According to the specifications presented in Table 1, all the members of the group of athletes fall within the prescriptions of Kyokushin sport.

The device used for investigations is HUBER 360. The Huber 360 is an apparatus with an oscillatory platform and 2 handles. It is equipped with force sensors located both under the motorized platform and at the level of the handles (Figure 1a). On the tablet on which the software (Figure 2b) HUBER 360 is integrated, you can view all the data recorded from the patient's evaluation, you can export the evaluation in PDF format that can be transmitted to the subject, allows 
personalized configuration of recovery programs and tracking the progress made by them Huber (2019), Chattanooga (2019).
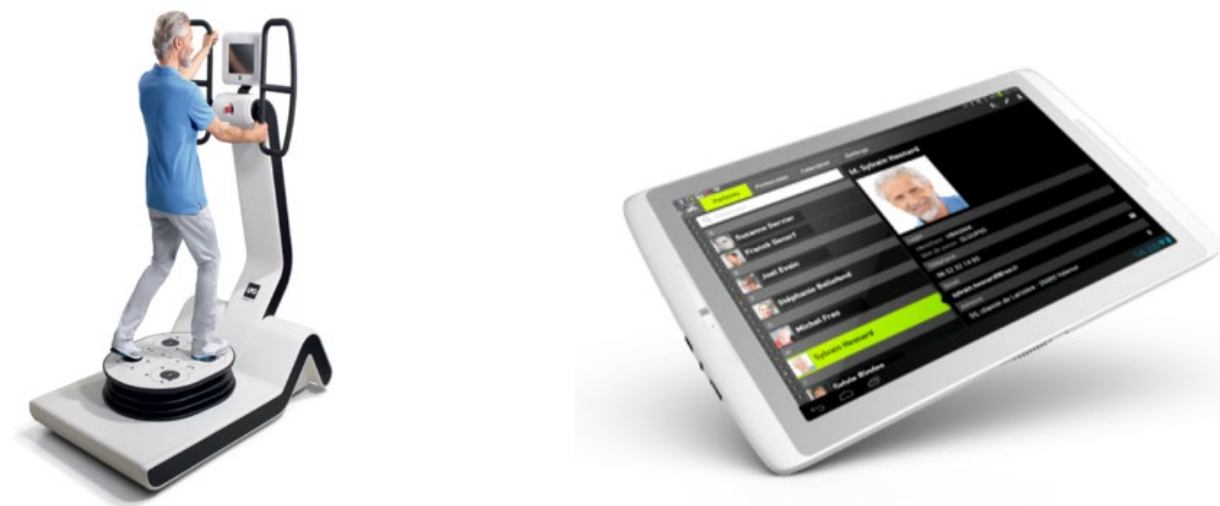

Figure 1 a. Huber 360 platform with a subject to investigate.

b. the tablet of the device with the subject's data

The device mobilizes the joints in all planes of movement in safe conditions and helps to relieve dysfunction, the feedback received on the screen helps the patient to improve the strength and coordination of movements, working during this component of the program both superficial and deep muscles. With the help of balance games adapted to the physical condition of the patient, improved stability, and self-confidence during the realization of movements can be achieved. In the last stage, dynamic exercises are performed through which the tolerance to effort can be increased, and the improvement of the cardiovascular system and the modification of the BMI can be observed Chattanooga (2015), Huber (2018).

With the help of this platform, we can assess the patient objectively through a number of 7 specific functional tests: Stability Test; Unipodal test; Gait test; Stability limit test; Mobility restrictions test; Test of the strength of the hind limbs; Upper and lower limb coordination test.

Chattanooga (2015). Of the 7 functional tests, 3 are based on the Romberg test and the Fukuda test and these assess balance, 2 focus on measuring the stability and mobility restrictions, and 2 focus on quantifying the force and assessing the coordination capacity of the subject Chattanooga (2019) In this paper for the investigation of the group of Kyokushin players, we will exemplify the stability test and the test of mobility restrictions.

\section{RESULTS AND DISCUSSIONS}

In practicing Kyokushin sport, the prelabyl investigation of athletes will be done in a succession of 4 tests, which consist of: stability test with open eyes, stability limit test, upper limb resistance test, upper and lower limb coordination test.

\subsection{TEST OF STABILITY WITH OPEN EYES}

The open-eyed stability test for the group of athletes is presented in Table 2, with the evidential values for each investigated subject, and the corresponding representations are found in Figure 2, Figure 3, Figure 4, Figure 5, Figure 6. The minimum values are marked with red and with blue the maximum values. 
Table 2 Centralization of stability measurements with open eyes for sportive

\begin{tabular}{cccc} 
Subject & $\begin{array}{c}\text { Stability - length (eyes } \\
\text { open) [ } \mathbf{m m}]\end{array}$ & $\begin{array}{c}\text { Stability - area (eyes } \\
\text { open) }\left[\mathbf{m m}^{2}\right]\end{array}$ & $\begin{array}{c}\text { Stability -speed (eyes } \\
\text { open) [mm/s] }\end{array}$ \\
\hline M1 & 753.46 & 476.28 & 15.07 \\
M2 & 587.11 & 174.25 & 11.74 \\
M3 & 521.94 & 261.1 & 10.44 \\
M4 & 526.85 & 177.72 & 10.54 \\
M5 & 777.5 & 171.13 & 15.55 \\
\hline
\end{tabular}

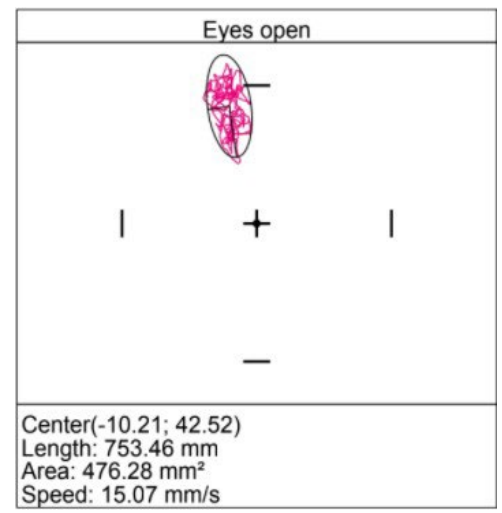

Figure 2 M1 stability (eyes open)

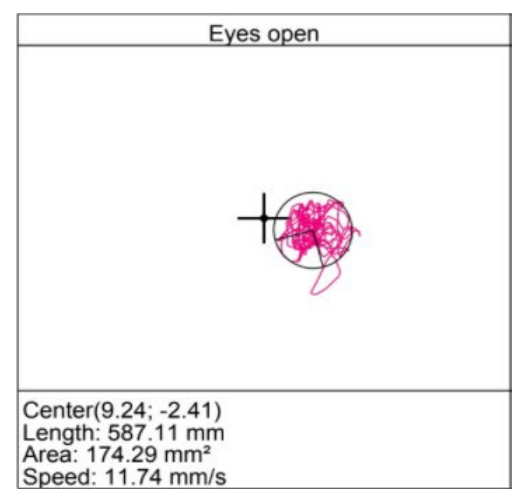

Figure 3 M2 stability (eyes open)

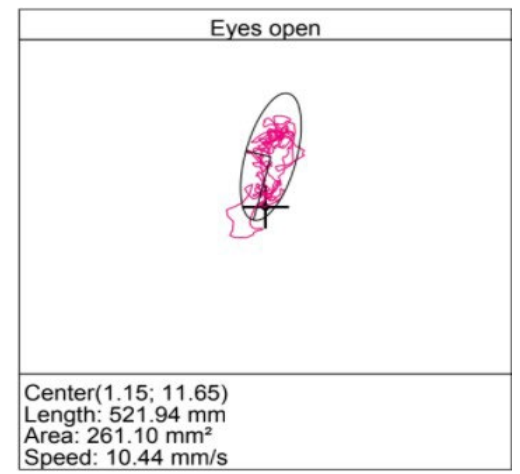

Figure 4 M3 stability (eyes open) 


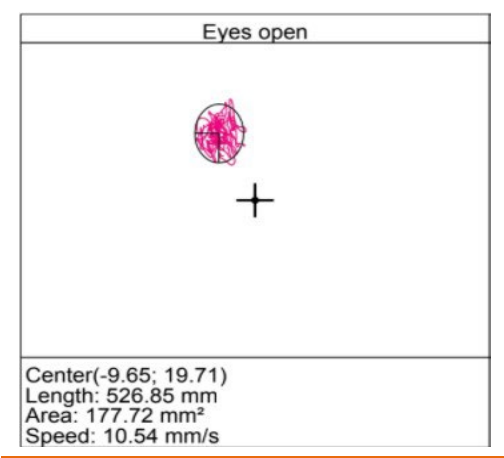

Figure 5 M4 stability (eyes open)

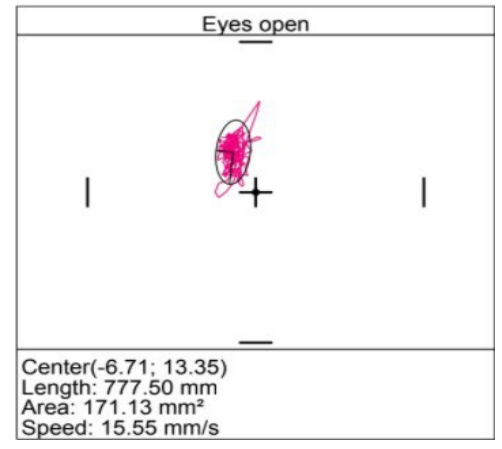

Figure 6 M5 stability (eyes open)

The stability test with eyes open shows the position of the subject's centre of gravity on the Huber 360's moving platform. The favourable aptitude of a subject compared to the others for one of the recorded quantities is presented in the tables for 15 minutes, as the test is carried out.

In the Table 2, and in the figures Figure 2, Figure 3, Figure 4, Figure 5, Figure 6 there are the registration data for the sportsman registrations. Using them we can conclude the followings:

- The subject M3 presents the smallest length of movement of the centre of gravity in this 15-minute time of performing the test, but also the lowest speed of movement of the centre of gravity during the test. So, this topic has the best stability in terms of moving the centre of the masses during the requests, which can arise in Kyokushin from the action of opponents during the competition.

- The subject M5 presents the smallest surface in the movement of the centre of gravity of the subject, the other sizes are maximum, so it is considered that the balance is not enough, to participate in competitions, it can be easily removed from the equilibrium position, and in order to balance it performs displacements in terms of length and high speed, which can lead to strong actions of the opponent. This athlete must do sustained training to be able to balance himself.

- The subject M1 has the maximum values for the area of the investigated measures, from this point of view, it is considered that, Kyokushin cannot be practiced for safety reasons, accidents/injuries can be frequent and uncontrolled. 


\subsection{STABILITY LIMIT TEST}

The stability limit test for the group of athletes is presented in Table 3, with the evidential values for each investigated subject, and the corresponding representations are found in Figure 7, Figure 8, Figure 9, Figure 10, Figure 11. The minimum values are marked with red and with blue the maximum values.

\begin{tabular}{|c|c|c|c|c|c|c|c|c|}
\hline Subject & $\begin{array}{c}\text { Limits of } \\
\text { stability } \\
1\end{array}$ & $\begin{array}{c}\text { Limits of } \\
\text { stability } \\
2\end{array}$ & $\begin{array}{c}\text { Limits of } \\
\text { stability } \\
3\end{array}$ & $\begin{array}{c}\text { Limits of } \\
\text { stability } \\
4\end{array}$ & $\begin{array}{c}\text { Limits of } \\
\text { stability } \\
5\end{array}$ & $\begin{array}{c}\text { Limits of } \\
\text { stability } \\
6\end{array}$ & $\begin{array}{c}\text { Limits of } \\
\text { stability } \\
7\end{array}$ & $\begin{array}{c}\text { Limits of } \\
\text { stability } \\
8\end{array}$ \\
\hline M1 & 144 & 224 & 232 & 221 & 140 & 210 & 243 & 207 \\
\hline M2 & 114 & 172 & 256 & 167 & 100 & 102 & 209 & 160 \\
\hline M3 & 113 & 187 & 235 & 228 & 160 & 222 & 229 & 150 \\
\hline M4 & 128 & 194 & 224 & 217 & 169 & 247 & 243 & 189 \\
\hline M5 & 126 & 178 & 266 & 76 & 101 & 156 & 254 & 157 \\
\hline
\end{tabular}

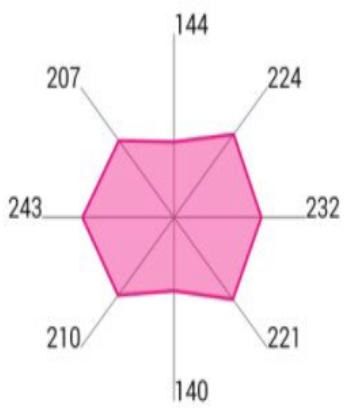

Figure 7 M1 stability limit test

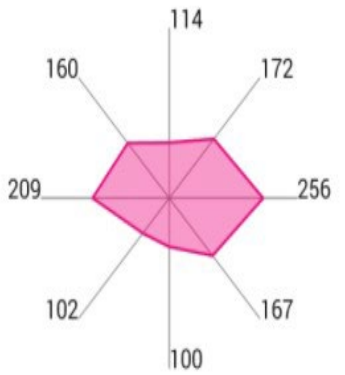

Figure 8 M2 stability limit test

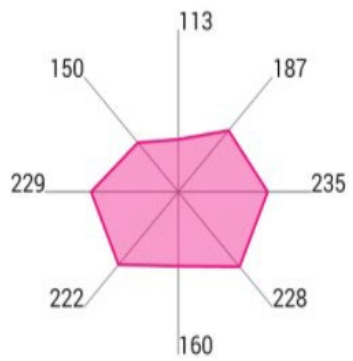

Figure 9 M3 stability limit test 


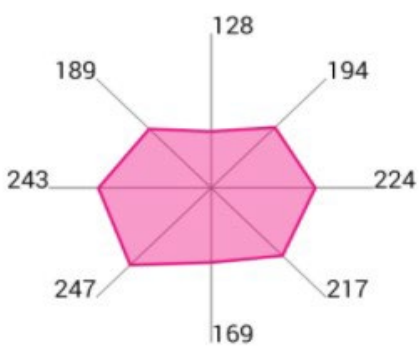

Figure 10 M4 stability limit test

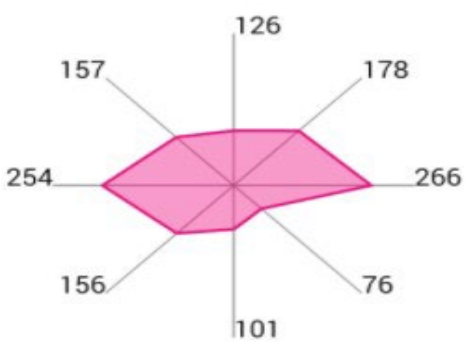

Figure 11 M5 stability limit test

The stability limit test involves transferring the body weight in one direction, without detaching the legs from the platform. The evaluation criterion is the maximum amplitude of the trunk and ankle, in 8 different directions Chattanooga (2015). The values recorded in the table represent the number on points accumulated in one direction out of the 8 , which the subject records during the 15minute test, during which the platform moves randomly. The minimum number of points denotes that in that direction the balance is better, while the large number signifies that the tendency to unbalance in that direction is higher. From the interpretation of Table 3 and figures Figure 7, Figure 8, Figure 9, Figure 10, Figure 11, the following aspects can be listed:

- The M1 sportive, compared to the other athletes, has greater instability in the directions: front, left-front, right front. On the other 5 directions it has medium stability. Stability can be considered average, from this point of view.

- The M2 sportive, compared to the other athletes in the group, has the best stability in the left-front, rear, right-rear, right-side, right directions, so it has good stability compared to the demands, to which it is subjected. It has good stability and can tow Kyokushin sport, as a performance athlete.

- The M3 sportive has good stability, compared to the other athletes in the directions: front, right-front, but has an instability found on the directions left-rear, right rear. This sportive must keep his back away from attacks because he is vulnerable.

- The M4 sportive has a median demean in general, an instability directly at the rear and an instability in the left-rear. This athlete is apt for Kyokushin.

- This sportive (M5) has strong stability in the rear and instability in the right front. He can practice Kyokushin with attention to the imbalance to the right. 


\subsection{UPPER LIMB RESISTANCE TEST}

The upper limb resistance test for the group of athletes is presented in Table 4, with the evidential values for each investigated subject, The minimum values are marked with red and with blue the maximum values. This test refers to the force of the upper limbs in isometric contraction, ironing the subject has his hands fixed on the handles of the device and acts with one hand or another by pulling or pushing.

\begin{tabular}{|c|c|c|c|c|c|}
\hline Subject & $\begin{array}{c}\text { Strength - } \\
\text { push left } \\
\text { [DaN] }\end{array}$ & $\begin{array}{c}\text { Strength - } \\
\text { push right } \\
\text { [DaN] }\end{array}$ & $\begin{array}{c}\text { Strength - } \\
\text { pull left } \\
\text { [DaN] }\end{array}$ & $\begin{array}{c}\text { Strength - } \\
\text { pull right } \\
\text { [DaN] }\end{array}$ & $\begin{array}{c}\text { Coordination } \\
\text { level }\end{array}$ \\
\hline M1 & 15 & 12 & -20 & -19 & 0 \\
\hline M2 & 10 & 13 & -13 & -13 & 0 \\
\hline M3 & 12 & 11 & -9 & -10 & 0 \\
\hline M4 & 8 & 7 & -10 & -11 & 0 \\
\hline M5 & 19 & 19 & -14 & -17 & 0 \\
\hline
\end{tabular}

From the analysis of Table 4 regarding the action of the superior memes, it is found that:

1) The M1 athlete has the best pulling behaviour, but it does not apply to this sport.

2) The M3 and M4 athletes have the push, respectively the weaker pull, so they will show caution in Kyokushin.

3) The M5 athlete has the best manifestation through the action by pushing the hands, so he is fit for practicing Kyokushin as a performance sport.

\subsection{UPPER AND LOWER LIMB COORDINATION TEST}

The open-eyed stability test for the group of athletes is presented in Table 4, with the evidential values for each investigated subject. In the Figure 12 there is the representation for each of them regarding this test.

The coordination test between the upper and lower limbs is closely related to the previous test because the subject is located on the platform, with his hands on the handles, and the athlete must push with the same force in both handles and maintain his balance on the platform. On the monitor screen appear different images, and the investigated one must be attentive to the received commands, to execute them according to the requirements.

Level achieved: 0

Time: 30 s

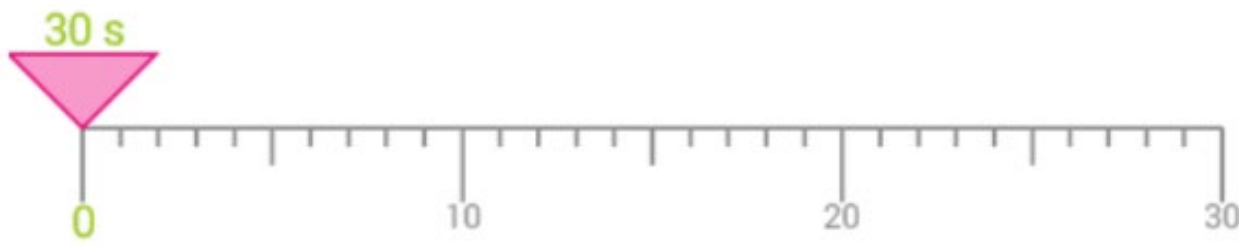

Figure 12 M1 - M5 upper and lower limb coordination test 
This test is especially important for athletes who practice Kyokushin because it requires their attention in the face, in order to react to the opponent's requests - in this case the screen of the device's monitor. This is a dynamic test. It was found that this dynamic test is very demanding for those investigated and manage to execute the commands for about 30 seconds. Figure 12 was introduced to exemplification of this test, because all athletes had the same behaviour and did not require the presentation of 5 figures almost. From Table 4 it results that none of those investigated managed to exceed the " 0 " level of the test and did not qualify for the next level. The tested athletes cannot cope for more than 30 seconds at the opponent's action, they will have to do sustained training for the application of Kyokushin, as a performance sport.

\section{CONCLUSIONSAND RECOMMENDATIONS}

The paper presents a preliminary test performed on five athletes who practice Kyokushin, as a performance sport. All athletes are part of the same team, so they are competitors only in training and not in competitions.

The test was performed with a specialized HUBER 360 device, which can perform 7 distinct tests on a platform that performs controlled movements, on which the competitor is positioned in an orthostatic position, with the soles of the feet placed by markings, which are posterior sensors, and the hands may or may not be put on some handles, where there is another category of sensors.

The tests were necessary to warn the athletes about the deficiencies that are detected in their behaviour under the action of external stimuli, to avoid injuries during competitions, or to direct the trainings in such a manner that the athlete's body is prepared for sports confrontations. The test results were communicated to the athletes.

The situation is as follows:

1) The M2 and M4 sportive are enough good the practice Kyokushin as performance sports.

2) M1 and M5 athletes have instability and accentuated imbalances, so training must be well directed to correct the inconveniences.

3) The M3 athlete is liable to injuries, so it would be good not to practice Kyokushin as a performance sport.

\section{REFERENCES}

Chattanooga. (2015). Integrated functional assessment. Retrieved from http://international. chattgroup. com/huber360/assessment.php

Chattanooga. (2019). Huber 360. Retrieved from https://www.chattanoogarehab.com/huber-360-15-0011-int

Emery, C. A., \& Pasanen, K. (2019). Current trends in sport injury prevention. Best practice \& research. Clinical rheumatology, 33(1), 3-15. Retrieved from https://doi.org/10.1016/j.berh.2019.02.009

Fuller C. W. (2007). Managing the risk of injury in sport. Clinical journal of sport medicine: official journal of the Canadian Academy of Sport Medicine, 17(3), 182-187. 
Huber 360. (2019). Https : //Www.Chattanoogarehab.Com/. Retrieved from https://www. chattanoogarehab.com/ huber-360-15-0011-int

Huber (2018). Technology LPG Medical.

Valle, X., Alentorn-Geli, E., Tol, J. L., Hamilton, B., Garrett, W. E., Jr, Pruna, R., Til, L., Gutierrez, and all. (2017). Muscle Injuries in Sports : A New EvidenceInformed and Expert Consensus-Based Classification with Clinical Application. Sports medicine (Auckland, N.Z.), 47(7), 1241-1253. Retrieved from https://doi.org/10.1007/s40279-016-0647-1 